\title{
Online Learning Cognition as Perceived by Undergraduate Students in China Eastern Province
}

\author{
Zezhao Liu ${ }^{1}$, Haifeng Tian ${ }^{2}$ \\ ${ }^{1}$ School of Public Administration \& Sociology, Jiangsu Normal University, \\ Xuzhou, China \\ Email: preliu [AT] yeah.net \\ ${ }^{2}$ Department of Business Management, Shaanxi Business College, \\ Xi`an, China \\ Email: $h f_{-}$tian $[A T]$ 163.com
}

\begin{abstract}
Company with global educational reform brought by digital governance and the challenge of COVID-19 pandemic in the year 2020, it is quite necessary to explore learners' recognition behaviors for on-line learning in the context of locked environment. By investigating on-line learning practices in China eastern provincial regions, the study attempts to disclose the undergraduate students' perceptions on the issues pertaining to on-line learning and the innate critical factors for individual intention through the selected region of relatively-developed eastern China. A survey design was used for the study, and a close-ended questionnaire with the six point Likert scale was developed regarding the issues over on-line learning practices. The findings indicate that instructor characteristics and teaching resources are the predictors of the perceived usefulness of on-line learning, and perceived usefulness coupled with the joyfulness are the predictors of on-line learning recognition. While statistically significant, perceived adaptability was shown to own the weakest effect for on-line learning recognition among the predictors. All these results are consistent with previous studies in other China regions, proving the universal trait of learners' perception and individual behavior towards on-line learning. Implications and future research are discussed eventually.
\end{abstract}

Keywords --- on-line learning; perception; influencing factor; China

\section{INTRODUCTION}

The most significant change in modern education practice during the past decade is the shift from traditional class room environment to a technology-supported on-line education, while the extensive on-line leaming has particularly accelerated after unprecedented strike by COVID-19 pandemics in 2020. Through the online platform, users can quickly share voice, video and data files with teachers, classmates, parents and others around the world by operating on the intemet interface. Essentially, on-line leaming is the application of modern information and communication technology to deliver any learning resources available to learners regardless of time, space or geographic proximity. Beyond all doubt, on-line learning environment is emerging as a brand-new paradigm in education form. Around the topic of on-line learning as well as great reform, it has drawn wide attention from many education-related entities, such as the higher education institutions, software developers, communities and business organizations due to the potential benefits and massive development prospect. Such benefits could reduce education cost with more consistency, flexible accessibility and convenience in educational products (Kahiigi \& Vesisenaho, 2013; Kelly \& Bauer, 2014). Nowadays in China, a large number of educational institution and social organization are offering online degree programs or training courses, expanding their educational practice without time and space restrictions. Business sectors are increasingly replacing offline job training with innovative online form, for the latter saves costs and enhances leaming effectiveness by delivering high-quality practical applications. Objectively speaking, the success of on-line learning largely depends on the implementation of a feasible educational mode which addresses the leamers' actual demands. As the application of on-line learning has extensively increased, it is necessary to unveil hidden factors affecting leamers' attitudes toward online learning, especially after the sudden emergency event hit the traditional conditions of leaming. Although it have previously investigated the certain factors under different work-task environment, there is still a lack of empirical studies that focus on the relationship among on-line learning and leamers' real recognition by themselves, particularly in the context of crisis condition like the COVID-19 pandemics. Thus, this research attempts to fill the gap in the specific setting of China, a nation with the largest on-line education market.

The fast development of on-line leaming in China is closely related to the rapid growth of information \& communication technology (ICT) industry as well as the strong administrative force. Actually, the Chinese government is 
driving power behind the stride of domestic on-line leaming or e-leaming. High-quality e-learning services as well as resources have been developed due to the techs of infrastructure facilities (ie. 5G technology) and the high-speed intemet support. Also, China's highly dense population and relatively high literacy rate provides cost-effective condition for elearning investment. Realizing the potential benefits of on-line leaming, many companies in China are increasingly adopting e-learning technique to train their employees especially the newly introduced college students and improve their skills. However, the propelling trend is diversified in different regions, as China is geographically imbalanced both in economic development level and educational resources. On the whole, eastem coast areas are more activated in promoting e-leaming than western one, and this meanwhile affects individual recognition as leamers set their goals based on the contextual features of the external environment.

Accordingly, the paper intends to investigate on-line learning recognition in eastern China from undergraduate students, and uncover those critical factors behind the options. In specific, this paper is organized in the following sections: firstly, it begins with the literature overview on e-learning discourse made by previous studies; secondly, it proposes the research hypotheses following by a instruction of the methodology. Thirdly, the statistical results were presented in Section 4 and the part of discussions. Conclusion will follow in the end section.

\section{LITERATURE REVIEW}

\section{A. Acceptance of}

The concept of on-line learning has long extended in academia but so far it has not been clearly agreed on over its scope of definition. Generally on-line learning is usually similar to e-leaming concept, which refers to any kinds of electronic device applications for learning purpose, including the delivery of information or knowledge via electronic media such as computer network, audio (or video tape), satellite broadcast, interactive TV and so on (Shee \& Wang, 2008, Sun et al., 2008). It is commonly accepted by more researchers that on-line learning can be undertaken by electronic media other than mere web-based media form. On-line leaming fulfils the learning requirements in the modem society and has created great demand from business to institute of higher education. Nowadays, on-line learning has become an indispensable part in the educational services market. Owing to high social demands, educational service providers offer online les sons, online tests, and educational consulting activities to meet diverse needs of the learners.

Modern on-line leaming is affiliated to active leaming mode, which is often contras ted to the traditional lecturing process where students passively receive information from the instructor in a gloaming atmosphere. Bouhnik \& Marcus (2006) point out the advantages of e-learning: freedom to decide leaming choice, convenience to reduce learning time constrains, adaptability to express thoughts without limitation, and accessibility of courses materials. Actually, the time and space resilience is the main element for the popular acceptance, as e-learning provides flexible conditions for mediabased, student-centred, and interactive environment that support active leaming (Ellis \& Goodyear, 2013; Alenezi,2018). Even though the potential benefits of e-leaming may be significant, there are also a number of limitation and challenge to actual practice. On one side, on-line leaming generally requires a high cost, pedagogical skills, learners' self-dis cipline and motivation (Giesber et al., 2013). Security issues such as cyber attack and cyber virus to e-leaming information system are of great concems to leamers and service providers (Ben, 2013). Additionally, in administering online tests, authenticating test-takers is one of the major challenges due to the inability to directly monitor the exam takers. To enhance the assessment of learning performance, some educational service providers or higher education institutions offer a mixture of online tests and offline tests, which further pushe-learning difficult to acquire its actual effects.

Various studies have suggested perceived effectiveness is a critical factor to affecting leamer attitudes toward on-line learning (Kramarski \& Gutman, 2016), while the degree of learner's satisfaction have been commonly us ed to evaluate the acceptance of e-learning (Eom, et al, 2006; Levy, 2007). Roca (2006) applied the Technology-Acceptance Model (TAM) for investigating learner intention toward e-leaming environment, and found that users' continuance intention is determined by satisfaction, which in tum is jointly determined by perceived usefulness, information quality, confirmation, service quality, perceived adaptability and cognitive absorption. Recently, Levy (2008) investigated issues related to learners' perceived value by uncovering the critical value factors of online leaming activities. His study identified five reliable CVFs that contribute to leamers' perceived value: (a) collaborative, social, and passive leaming activities; (b) formal communication activities; (c) formal learning activities; (d) logistic activities; and (e) printing activities.

\section{B. Factor of e-learning Recognition}

Despite the potential of on-line leaming serves as a tool to enhance education and training performance, its value will not be realized if users do not accept it as a learning tool. When designing an on-line course, instructors faced with lots of considerations that consequently affect how students desires, construct and process external information. Indeed, students' recognitions of on-line leaming are positively related to perceived leaming effects, which usually includes 
learning outcomes, individual achievements and course satisfaction (JL. Holmgren \& S. Bolkan, 2014). Herein, this paper apply certain constructs (perceived usefulness \& perceived adaptability) to assess students real recognition of online courses, and results revealed that perceived us efulness and perceived adaptability proved to be key determinants of the recognition as an effective learning channel. To understand an engineer's recognition of e-learning, Bouhnik et al (2006) proposed a construct, perceived credibility, which measures the degree to which a person believes that a particular system would be free of privacy and security threats. Their empirical study supports that perceived credibility has a positive effect on engineers' leaming recognition. Other factors are cited by the closeness and application ripeness, such as leamer $\mathrm{IT}$ technology anxiety, instructor attitude toward e-leaming, course flexibility, course quality, and divers ity in ass ess ment, which also seem to affect learners' recognition satisfaction (Sun, Tsai, Finger, et al. 2008). Roca \& Gagné (2008) introduced three motivational factors, perceived autonomy support, perceived competence, and perceived relatedness. Actually, to enhance on-line learning outcomes, strengthening individual satis faction is a necessity and ought to be put into the analysis framework.

Fig. 1 presents some related elements based on previous studies.

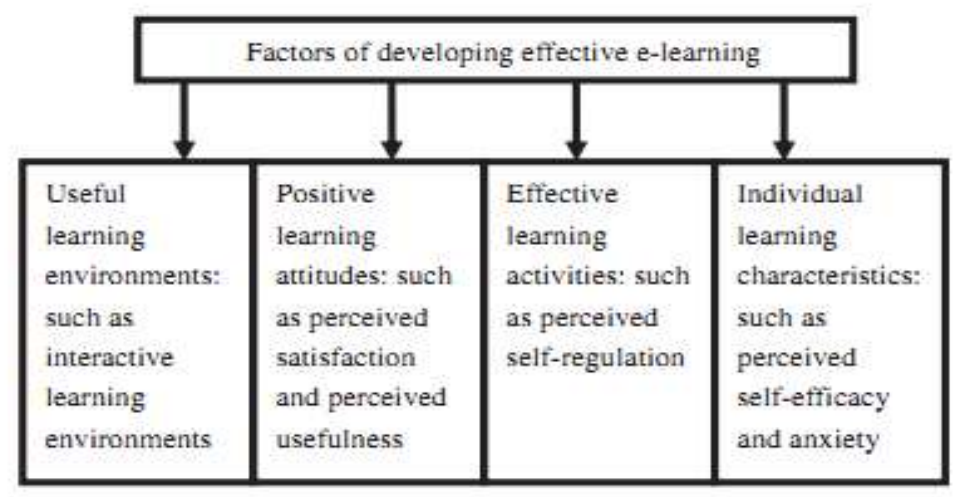

Fig. 1 Elements of developing effective e-learning condition (adapted from Liaw [2013]).

A few e-learning studies mean while address contribution of joyfulness to instructor and leamers recognition of online learning service. Pituch \& Lee (2006) captured both extrinsic and intrinsic motivators for explaining students learning recognition services. Shee \& Wang (2008) also advised that four dimensions be considered when evaluating online learning: user-friendly learner interface, interactive learning community, us eful system content, and personalization. These research results showed that the individual emotional factors impacted students e-learning recognition. On the other hand, perceived adaptability did not have a significant effect on attitude or e-leaming recognition. Our literature review reveals that further res earch is still needed to understand joyfulness and the adoption of on-line learning.

\section{MODEL AND HYPOTHESIS}

\section{A. Model}

Based on the literature review, this paper believes that on-line learning is needed to assess the individual recognition by current learners with specific environment. It thus proposed a theoretic model which consists of both independent variable and dependent variable. The independent variables are joyfulness and service quality constructs, including instructor traits, teaching resources and learning design. Specifically, instructor traits are defined as the extent to which instructors are helpful and easygoing to undergraduate learners. Teaching resources are defined as the extent to which teaching materials are suitable for on-line leaning. Learning design is defined as the extent to which learning contents are adequately designed and developed to fit learners needs. Other two variables are perceived usefulness and perceived adaptability. Perceived usefulness herein indicates the degree to which an undergraduate believes that a particular on-line learning service would enhance his/her learn ing performance and bring feasible benefits. Perceived adaptability is the degree to which an undergraduate believes that on-line learning is easy to acquire and smoothly applicable. The dependent variable in this research is the individual recognition of on-line learning.

\section{B. Hypotheses}

Previous study showed that Instructor' s attitude and competence affect learners' attitude, and instructor's teaching style affects learners' enthusiasm in study participation as well as the attitude toward e-learning (Webster \& Hackley, 1997; Wang, 2016). An empirical study on student attitude reveals that traits of instructor are the most critical factor in e-learning success, followed by IT infrastructure and university support (Selim, 
2007). A similar study suggests that the quality of e-learning course affect learners' perceived satisfaction (Sun et al., 2008). Based on these research above, the article tends to establish hypothesizes as follows:

\section{a. Hypothesis 1}

From the abovementioned literature review, it can see that instructor serves as one vital role in transmitting the online learning value. Thus we proposed hypothesis $\mathrm{I}(\mathrm{H} 1)$ :

Instructor characteristics positively affectlearners' perceived usefulness for on-line leaning.

\section{b. Hypothesis 2}

Learners will be more inclined to feel that the e-learning services is easy if e-leaming services are provided with plentiful content designed to meet their needs. In the on-line context, learner-centred services which provide learners with contents of accuracy and consistency will facilitate perceived on-line learning. Thus the article makes the following hypothesis:

Teaching resources positively affect learners' perceived usefulness in on-line learning context.

\section{c. Hypothesis 3}

In e-learning settings, researchers indicate that perceived adaptability affects application directly and indirectly through perceived usefulness (Venkatesh \& Davis, 2000), and the factor positively affects the perceived usefulness (Pituch \& Lee, 2006). Thus, it hypothesized as follows:

Learning design positively affects learners' perceived on-line learning adaptability.

\section{d. Hypothesis 4}

Previous research suggests that success of e-leaming depend on continued usage (Chiu, Hsu, Sun, Lin, \& Sun, 2005). Also it indicated perceived usefulness contribute to leamers' intention to use on-line learning system (Liaw, 2008). Thus, it hypothesized as follows:

Learners' perceived adaptability in on-linelearning environment positively affects leamers 'perceived usefulness.

\section{e. Hypothesis 5}

One goal is obvious that learners intend to acquire useful knowledge and scientific sources, thus a sound criteria in e-learning is affiliated with actors perception in the learning process. Based on this point, it hypothesized as follows:

Learners' perceived usefulness positively affects the intention to on-line learning.

\section{f. Hypothesis 6}

On point is certain that, learning is a kind of game which leamers not only acquire knowledge but also innate satisfaction, especially in the web-based environment. Nowadays, more and more researchers as well as the common people hold the view that "leaming forplay on the intemet", that cybers pace leaming with certain playing forms provides an irreplaceable channel for modern on-line learning. Thus it make the following hypothesis:

The joyfulness of on-line learning positively affects individual intention to on-linelearning.

\section{METHODOLOGY}

\section{A. Questionnaire}

To test the hypotheses proposed in this study above, the research used a questionnaire survey as the methodological tool to obtain response from the sample undergraduate students in eastem China. As the first step, a pilot study with online interviews was carried out in the survey, in which random college students from eastern Jiangsu province were selected and urged to give their ideas of extensive on-line learning that they consider to be most important, particularly in the 2020 covid-19 pandemics. By a content analysis, all the student answers were categorized and the frequency of answers in different categories were further determined.

Utilizing the feedback from the pilot study and at the same time considering the characteristics of surveyed samples, the questionnaire were further adjusted. Eventually, the revised questionnaire contains the following items for afterward testing: (a) an evaluation of undergraduate expectation of on-line leaming; (b) the individual feeling of on-line leaming experiences; (c) the assessment of learning course outcome (including the learning achievement, the course satisfaction); (d) the demographic questions.

In the first section, undergraduate students evaluated the importance of on-line learning on a six-point Likert scale (ranging from 1 "not important at all" to 6 "very important"). In the second section, the surveyed students are demanded to evaluate some claims that describes positive or negative experiences on similar scale (ranging from 1 "I disagree completely" to 6 "I agree completely"). In the third section, they are requested to assess their on-line satis faction (scale ranging from 1 "very low achievements/satis faction" to 6 "very high achievements/satis faction"). In other words, scale items in the questionnaire are all developed based on the existing literature discussed in previous studies as well as the pilot test from the first testing procedure. The variables in the constructed research model are also encompassed in the following items: the instructor traits/characteristics, the teaching resources, the leaming design, joyfulness, perceived 
usefulness, perceived adap tability and on-line learning recognition.

Table 1 shows the operational definition of each variable mentioned.

\section{B. Data collection}

For data collection, we dispatched interviewers to various high-level educational institutions as university, college and vocational schools of undergraduates during the period time in 2019-2020 from Jiangsu Province, one eastem province of China. The survey member briefed the interviewers on the key research objective as well as the background references. To enhance the quality of data collection process, at the outset all interviewers were professionally trained on interview techniques, and also it were assured the key information that their responses will be kept confidential. Clearly, these procedures preformed could largely minimize potential misinterpretation of question items and enhanced the data collection quality.

In total 290 undergraduate students and leamers who had attended at least one on-line leaming courses, either in school or at home, participated in the study with anonymity. By statistics, over 95\% of the participants are aging from 18-30 years old; $16 \%$ are freshmen, $38 \%$ sophomores, $32 \%$ juniors, and left seniors. Of the 290 standard questionnaires in distribution, 18 were not completed validly and 17 were not retumed, leading to eventual 271 valid responses (a response rate of $93.4 \%$ ). Also, we collected students' final scores to examine the relationship between their perceptions of perceived support and on-line learning outcomes.

Table 1. Variables and the corresponding operation definition

\begin{tabular}{ll}
\hline \multicolumn{1}{c}{ Construct variable } & \multicolumn{1}{c}{ Operation definition } \\
\hline $\begin{array}{l}\text { instructor } \\
\text { teaching resources }\end{array}$ & $\begin{array}{l}\text { the extent to which instructors are concerning to students } \\
\text { the extent to which teaching materials are suitable } \\
\text { learning design } \\
\text { joyfulness }\end{array}$ \\
the extent to which learning contents are better designed for learners \\
the extent to which students enjoy on-line learning \\
the extent to which learners admit the economic utility \\
perceived adaptability & $\begin{array}{l}\text { the extent to which learners believe that on-line learning will be easy } \\
\text { to get access }\end{array}$ \\
\hline
\end{tabular}

The courses selected for this research combined both from on-line learning and traditional face-to-face pathway. Both synchronous and asynchronous web-based technologies were applied for the on-line learning support. The asynchronous on-line leaming support includes online lecture notes, online quizzes, online announcements of institutions, online assignments, electronic student-student \& student-instructor communication, audio \& video streaming. The synchronous on-line learning support includes herein the chat and video conferencing.

\section{DATA ANALYSIS}

\section{A. Reliabilityand Validity Analysis}

We use SPSS 23.0 to analyze the data. The responses from the questionnaire were coded, checked for missing responses, scored and subjected into SPSS software, and then analyzed using descriptive inferential statistics. Given the theory-driven approach to scale development, scale validation was done using classic Exploratory Factor Analys is (EFA) and Confirmatory Factor Analysis (CFA). The factor analys is utilized the principal component extraction method and way of Varimax rotation. It required that factor loadings exceed 0.50 . After factor analyzing one item from Instructor Characteristics, one item from Knowledge Transmitting Resources, and three items from Learning Design were deleted due to a low factor loading. While four items were removed from the three factors in the independent variables, no items were deleted from the two belief variables and the dependent variable. The high reliability of these variables can be attributed to fact that numerous previous studies validated the factor items.

The questionnaire used the Cronbach's a coefficient to test the intemal consistency among items of the same construct. According to Guieford (1965), a Cronbach's a value that is greater than 0.7 indicates high reliability and less than 0.35 represents unacceptable reliability. A Cronbach's value between 0.35 and 0.7 has fair but acceptable reliability. Researchers suggest Cronbach alpha of 0.70 for confirmatory research and 0.60 for exploratory research could be acceptable (Hair, Anderson \& Black, 1998). The reliability values of the constructs are in the range of 0.692-0.889 suggesting acceptable reliability. 
Cumulative variance explained for the variables are measured to be acceptable, namely, 59.73\% for the independent variables; $81.33 \%$ for the belief variables; and $73.1 \%$ for the dependent variable. The factor loading values of all indicator variables are over 0.506 , far exceeding 0.30 , which is considered the minimum loading for interpretability. Overall, all these results suggest that the constructs exhibit appropriate psychometric properties and the model fits well with the data.

\section{B. Hypotheses testing}

Although the structural equation modeling (SEM) has advantages over traditional statistical techniques like the regression way, it is recommended that a model with two to four factors, it could be better for an investigator plan on collecting at least 100 cas es. Due to the smaller sample size than recommended, a regression model herein is applied for testing the hypotheses proposed.

Table 2 summarizes the tes ting results of the modelabove.

Table 2. Testing results for the constructed model

\begin{tabular}{|c|c|c|c|}
\hline Relations between variables & B & t-value & p-value \\
\hline instructor characteristics $\rightarrow$ perceived usefulness & 0.631 & 5.821 & $0.000^{* *}$ \\
\hline$\rightarrow$ perceived adaptability & 0.373 & 4.012 & $0.000^{* *}$ \\
\hline perceived adaptability $\rightarrow$ perceived usefulness & 0.591 & 5.982 & $0.000^{* *}$ \\
\hline perceived usefulness $\rightarrow$ on-line learning recognition & 0.507 & 11.029 & $0.000^{* *}$ \\
\hline perceived adaptability $\rightarrow$ on-line learning recognition & 0.183 & 2.604 & $0.019 *$ \\
\hline perceived playfulness $\rightarrow$ on-line learning recognition & 0.451 & 9.921 & $0.000^{* *}$ \\
\hline
\end{tabular}

To test whether there is an increment in the proportion of variance accounted for by model modification, F-test was us ed to examine the significance of change in the square of multiple correlation coefficients. Results shows that the value of $\Delta \mathrm{R}^{2}$ is $0.017(\mathrm{p}<0.01)$, and the $\mathrm{R}^{2}$ value is $0.035(\mathrm{p}<0.001)$. Totally, in all cases, the $\Delta \mathrm{R}^{2}$ were significant, indicating improvements overall are fit in the model when adding additional variables in the hierarchical regression.

\section{DISCUSSION AND CONCLUSION}

Focusing on individual cognition for on-line leaming, this article developed a framework to explain what factors would facilitate on-line leaming for undergraduates, and empirically tested the constructed model by the data obtained from Chinese colleges.

In this study, it analyzed leamers' recognition of on-line leaming from on-the-training student pers pectives in context of Eastern China. Results indicate that leamers tend to be more positive towards online leaming when considering their temptation. Actually, as internet technologies advance, online leaming service providers can enhance leaming products without additional costs by taking advantage of the declining cost, thus resulting in greater adoption by leamers. Among the variables of testing, perceived usefulness is the greatest predictor of online learning recognition. The result also indicates that perceived usefulness has a positive effect on learning recognition. Additionally, the perceived usefulness can be strengthened by providing enhanced online learning services without increasing the complexity of online leaming process. Finally, perceived joyfulness positively affects the online leaming recognition. One of the recent tendencies in education services is to improve the outcomes by incorporating personal amusement. Educational institutions need to provide adequate resources to instructors and train to use a variety of educational tools innovatively. Periodic survey and assessment of entertainment tools for educational use seem worth conducting. Future research is needed to fully unders tand the relationships between student characteris tics of different varieties and online leaming service quality that improve or undermine learners' intention to use online learning.

Apart from the theoretic contribution, the results of this study have important implications for practitioners of bus iness sectors. It provides educational institutions with some guidance on how to use effective strategies to facilitate online learning market in China. In emerging economies, online learning is "a big cake" to explore and could help firms achieve potential profits. However, business sectors should also be aware that indigenous demands in context of competitive China is a complex side that requires effective "operating mechanism", and firms should better understand the innate social recognition in accepting online learning. On the whole, this study advances the understanding of online leaming for undergraduates at a time when on-line course is assumed to be of importance in the competitive China online market. As online leaming is increas ingly adopted by educational institutions and comorations, it needs to evaluate and take into 
consideration for the individual recognition from online learning system. Educators need appropriate supporting policies for addressing technical issues and emerging problems that students may face in technology-incentive conditions. At the same time, China's dense population and high educational standards make investment on e-learning very cost-effective.

Inevitably, there are limitations in the study. First, there is reason to be cautious in generalizing selected data in Easter China to other regions because of the context-specificity. More closer studies for contextual differences are necessary before generalizing the findings to other settings. Second, the data used in the study fails to allow causal interpretation among the factors. Ideally, this study would have benefited from a time lag between the measurement of the independent and dependent variables for causal relationships determined. Future research needs to include more influencing factors to build an integrated model. Furthermore, it needs to address the perceptions of other individuals apart from undergraduate like the employees, and cross-cultural online leaming research may expose more new insights as the world gets closely intertwined by the internet.

\section{ACKNOWLEDGMENTS}

This research is supported by Shaanxi "Thirteen-five Year Plan" Education Science Foundation of mainland China under Res earch Grant (SGH16V021). We would like to extend our thanks to Dr. Zhang Q., Shaanxi Normal University for his sincere support.

\section{REFERENCES}

[1] Kahiigi E K, Ves is enaho M, Tusubira F F, et al. "Peer Assignment Review Process for Collaborative E-learning: Is the Student Leaming Process Changing?" Intemational Joumal of Advanced Computer Science \& Applications, vol.3, no.12, pp.1-7. 2013.

[2] Sun, P. C., Tsai, R. J., Finger, G., Chen, Y. Y., \& Yeh, D. "What drives a successful e-leaming? An empirical investigation of the critical factors influencing leamer satisfaction". Computers \& Education, vol.50,no.4, pp.11831202. 2008.

[3] Shee D Y, Wang Y S. "Multi-criteria evaluation of the web-based e-leaming system: A methodology based on learner satisfaction and its applications". Computers \& Education, vol.50, no.3, pp.894-905. 2008.

[4] Al-Busaidi K A, Al-Shihi H. Key factors to instructors' satisfaction of leaming management systems in blended learning[J]. Journal of Computing in Higher Education, vol.24, no.1, pp.18-39. 2012.

[5] Motiwalla, L. F. "Mobile learning: a framework and evaluation". Computers \& Education, vol.49, no.3, pp.581596.2007.

[6] Bouhnik, D., \& Marcus, T. "Interaction in distance-leaming cours es". Journal of the American Society Information Science and Technology, vol.57, no.3, pp.299-305. 2006.

[7] Ellis R A, Goodyear P. "Students' experiences of e-leaming in higher education: the ecology of sustainable innovation". Students' Experiences of e-Learning in Higher Education. 2013.

[8] Ben-Asher N, Gonzalez C. "Effects of cyber security knowledge on attack detection". Computers in Human Behavior, vol.48, no. 4, 51-61.2015.

[9] Giesbers B, Rienties B, Tempelaar D, et al. "Investigating the relations between motivation, tool use, participation, and performance in an e-leaming course using web-videoconferencing". Computers in Human Behavior, vol.29, no. 1, pp. 285-292. 2013.

[10] Alenezi A M. "E-learning in Higher Education”. Journal of Tianjin University of Technology \& Education, vol.3, no.2, pp.1-14. 2018.

[11] Eom, S. B., Wen, H. J., \& Ashill, N. "The determinants of students' perceived learning outcomes and satis faction in university online education: An empirical investigation”. Decis ion Sciences Joumal of Innovative Education, vol.4, no.2,pp.215-235. 2006.

[12] Levy, Y. "Comparing dropouts and pers istence in e-leaming courses". Computers and Education, vol.48, no. 2. pp. 185-204. 2007.

[13] Roca J C, Gagné M. "Unders tanding e-learning continuance intention in the workplace: A self-determination theory perspective". Computers in Human Behavior, vol.24, no.4,pp.585-1604. 2008.

[14] Kramarski, B., \& Gutman, M. "How can self-regulated learning be supported in mathematical E-learning environments?" Journal of Computer Assisted Learning, vol. 22, no.1, pp.24-33.2016.

[15] Selim, H. M. "E-learning critical success factors: An exploratory investigation of student perceptions". Intemational Journal of Technology Marketing, vol.2, no. 2, pp.157-182. 2007.

[16] Venkatesh, V., \& Davis, F. D. “A theoretical extension of the Technology Acceptance Model: Four longitudinal field studies”. Management Science, vol.46, no. 2, pp.186-204. 2000.

[17] Pituch, K., \& Lee, Y. "The influence of system characteristics on e-learning use". Computers and Education, vol.47, no.2, pp.222-244. 2006.

[18] Chiu, CM., Hsu, MH., Sun, SY., Lin, TC., \& Sun, PC. "Usability, quality, value and e-learn ing continuance decisions". Computers and Education, vol.45, no.4, pp.399-416.2005. 
[19] Roca J C, Chiu C M, Martínez F J. "Understanding e-learning continuance intention: An extension of the Technology Acceptance Model". International Journal of Human-Computer Studies, vol.64. no.8, pp.683696. 2006.

[20] Holmgren J L, Bolkan S. "Instructor Responses to Rhetorical Dissent: Student Perceptions of Justice and Classroom Outcome". Communication Education, vol.63, no.1, pp.17-40. 2014.

[21] Liaw S S, Huang H M. "Perceived satisfaction, perceived usefulness and interactive learning environments as predictors to self-regulation in e-learning environments". Computers \& Education, vol. 60, no.1,pp.14-24. 2013.

[22] Liaw, S. S. "Investigating students' perceived satisfaction, behavioral intention, and effectiveness of e-learning: A case study of the Blackboard system". Computers and Education, vol.51, no.2, pp.864-873. 2008.

[23] Shee, D., \& Wang, Y. H. "Multi-criteria evaluation of the web-based e-leaming system: a methodology based on learner satisfaction and its applications". Computers \& Education, vol.50, no.3, pp.894-905. 2008. 